\title{
Reliability and validity of an equanimity questionnaire: The two-factor equanimity scale (EQUA-S)
}

\author{
Catherine Juneau $^{\text {Corresp., } 1}$, Nicolas Pellerin ${ }^{2}$, Elliott Trives ${ }^{3}$, Matthieu Ricard ${ }^{4}$, Rebecca Shankland ${ }^{5}$, Michael \\ Dambrun $^{1}$ \\ 1 LAPSCO CNRS UMR 6024, Université Clermont Auvergne, Clermont-Ferrand, France \\ 2 CLLE-LTC CNRS UMR 5263, Université de Toulouse-le-Mirail (Toulouse II), Toulouse, France \\ 3 LAPCOS, Université de Nice-Sophia Antipolis, Nice, France \\ 4 Mind and Life Institute, Shechen Monastery, Kathmandu, Nepal \\ 5 LIP/PC2S, Université Pierre Mendes-France (Grenoble II), Grenoble, France \\ Corresponding Author: Catherine Juneau \\ Email address: catherine.juneau@uca.fr
}

Background. Many studies have revealed the positive impact of mindfulness training on mental health and proposed equanimity as a general outcome in contemplative research. Despite recent interest, relatively few studies have empirically examined equanimity, and measurement instruments are still lacking. The main goal of this study was to develop an Equanimity Scale (the EQUA-S) in a Western population with or without meditation experience, based on previous definitions of equanimity, in order to investigate its relations with the relevant psychological constructs and health outcomes. Methods. Adults from the general population ( $N=265 ; M_{\text {age }}=34.81$ ) completed various measures: the EQUA-S, mindfulness, hyper-sensitivity, avoidance and fusion, impulsivity, personality, alexithymia, sensitivity to punishment and reward, and frequency of problematic addictive behaviors. The dimensionality of the EQUA-S was examined using Factor Analyses. The convergent validity of this new scale was investigated using Pearson's Correlations.

Results. The results of a factor analysis revealed two dimensions of equanimity: an evenminded state of mind (E-MSM) and a hedonic independence (HI) component. While the EMSM was positively related to emotional stability, adaptive emotional regulation, and several mindfulness-related abilities, $\mathrm{HI}$ was found to correlate negatively with addictive issues. Discussion. The relations with personality constructs and possible related cognitive processes are discussed. 


\section{Reliability and validity of an equanimity questionnaire: 2 The two-factor equanimity scale (EQUA-S)}

3

4

5

6

7

8
Catherine Juneau ${ }^{1}$, Nicolas Pellerin ${ }^{2}$, Elliott Trives ${ }^{3}$, Matthieu Ricard ${ }^{4}$, Rebecca Shankland ${ }^{5}$, Michael Dambrun ${ }^{1}$

${ }^{1}$ LAPSCO, CNRS UMR 6024, Université Clermont Auvergne, Clermont-Ferrand, France ${ }^{2}$ CLLE-LTC, CNRS UMR 5263, Université Toulouse 2 Jean Jaurès, Toulouse, France ${ }^{3}$ LAPCOS, Université Sophia Antipolis, Nice, France.

${ }^{4}$ Mind and Life Institute, Shechen Monastery, Kathmandu, Nepal

${ }^{5}$ LIP/PC2S, F-38000, University Grenoble Alpes, Grenoble, France

Corresponding Author:

Catherine Juneau and Michael Dambrun

Université Clermont Auvergne (UCA), LAPSCO CNRS, 34 avenue Carnot, 63037, France

Email: catherine.juneau@uca.fr and michael.dambrun@uca.fr 


\section{Abstract}

42

Background. Many studies have revealed the positive impact of mindfulness training on mental health and proposed equanimity as a general outcome in contemplative research. Despite recent interest, relatively few studies have empirically examined equanimity, and measurement instruments are still lacking. The main goal of this study was to develop an Equanimity Scale (the EQUA-S) in a Western population with or without meditation experience, based on previous definitions of equanimity, in order to investigate its relations with the relevant psychological constructs and health outcomes.

Methods. Adults from the general population $\left(N=265 ; M_{\text {age }}=34.81\right)$ completed various measures: the EQUA-S, mindfulness, hyper-sensitivity, avoidance and fusion, impulsivity,

52 personality, alexithymia, sensitivity to punishment and reward, and frequency of problematic addictive behaviors. The dimensionality of the EQUA-S was examined using Factor Analyses.

54 The convergent validity of this new scale was investigated using Pearson's Correlations.

55 Results. The results of a factor analysis revealed two dimensions of equanimity: an even-minded state of mind (E-MSM) and a hedonic independence (HI) component. While the E-MSM was

57

62 positively related to emotional stability, adaptive emotional regulation, and several mindfulnessrelated abilities, HI was found to correlate negatively with addictive issues.

Discussion. The relations with personality constructs and possible related cognitive processes are discussed. 
65

66

67

68

69

70

71

72

73

74

75

76

77

\section{Introduction}

Mindfulness has been defined as paying non-judgmental and non-reactive attention to the present moment. The practice of mindfulness-based meditation has been found to have a robust effect on a variety of psychological outcomes, such as changes in emotionality, relationship issues, attention, and health (Sedlmeier et al., 2012). Several psychological and neurological mechanisms underlying these effects have been identified (Gu et al., 2015). In Buddhism, mindfulness meditation is a way to achieve an attentional, emotional, and cognitive balance of the mind (Ekman et al., 2005), a mental state which can be termed equanimity. Many authors have suggested using equanimity as a general outcome in contemplative research (Desbordes et al., 2015; Hadash et al., 2016), but existing mindfulness scales do not take this primordial quality into account (Weber, 2017).

In the Abhidhamma Sangaha (Bodhi, 2012), a classical Buddhist text from the Theravada tradition, and also in the Mahayana teachings on Buddhist psychology (i.e., lorig in the Tibetan tradition; e.g., Gyatso, 2002), equanimity (Upekkhā in Pali) is defined in various forms, including equanimity as a feeling, immeasurable equanimity, and equanimity as a mental attitude. Equanimity as feeling refers to a way to neutrally experience an object, or in other words, with a "neither-painful-nor-pleasant feeling" (Bodhi, 2012, p.115). Immeasurable equanimity forms part of the meditation practice on the Four Immeasurables (love-kindness, compassion, joy, and equanimity), which aim to develop a deep sense of compassion and care in an individual towards all living beings by iteratively familiarizing them with these four states (Wallace, 2010). Finally, equanimity is also defined as a balanced mental attitude or quality of mind, with unbiased reactions to things. More specifically, all objects, situations, thoughts, and emotions are considered and processed evenly, manifested by an attitude of neutrality toward all 
90 stimuli. This mental attitude of equanimity is the definition used in psychology (Desbordes et al.,

91 2015), and is the focus in this article. Indeed, equanimity as a quality of mind can be developed

92 by means of mindfulness-based meditation (Juneau, Shankland, \& Dambrun, in press), and has

93 recently been theoretically introduced into Western psychology as a beneficial effect of this

94 practice (Pagis, 2015) based on the Buddhist conceptualization (Dambrun \& Ricard, 2011).

95 Equanimity has been studied and described by Buddhists because they believe that

96 developing this quality towards objects, thoughts, feelings, and living beings leads to a decrease

97 in suffering (duhkha in Pali) and an increase in happiness (sukha in Pali). In this context,

98 suffering refers not only to physical pain or sadness, but also to a more all-encompassing sense

99 of continuing dissatisfaction which is caused by a self-centered perspective in which feelings and

100 thoughts repeatedly and automatically arise, and are vividly perceived and interpreted as "real"

101 and as part of a stable conception of self (Dambrun \& Ricard, 2011). However, mindfulness-

102 based meditation allows practitioners to focus their attention on each of the sensations that make

103 up this stream (i.e., mental proliferation or rumination) and to perceive them for what they are in

104 the present moment: mental events, rather than a fixed reality (Holzel et al., 2011). With practice,

105 the conception of the self may change, the flow of these mental events may become less

106 automatic, and habitual reactions may appear less frequently. Thus, the Buddhist conception of

107 happiness, which involves "mental balance and insight into the nature of reality" (Ekman et al.,

108 2005, p.60), can arise when an individual is free from these frustrations. Craving, for example, is

109 one of the principal causes of frustration in Buddhist theory, and is conceptualized based on

110 similar constructs to those of its Western definition. However, while the Buddhist conception of

111 craving includes all afflictive attachments (e.g., striving to achieve a promotion, struggling to

112 stop thinking about someone; see Groves \& Farmer, 1994), Western psychology defines craving 
113 more specifically as an intense desire directed toward objects or situations, resulting in addictive

114 behaviors (Skinner \& Aubin, 2010). Indeed, various studies have consistently shown a decrease

115 in addictive craving after mindfulness-based meditation (e.g., Lacaille et al., 2014). Thus, the

116 development of equanimity could explain positive effects on addictive behaviors after practices,

117 as well as a large range of positive outcomes such as prosocial attitudes (Hadash et al., 2016;

118 Romm, 2007; Weber, 2018).

119 Equanimity can be defined as a calm and stable attitude, free of tortuous emotional

120 reactions. This echoes the approach adopted by Desbordes et al. (2015), who defined equanimity

121 as "an even-minded mental state or dispositional tendency toward all experiences or objects,

122 regardless of their affective valence (pleasant, unpleasant or neutral) or source” (p. 6). Vago and

123 Silbersweig (2012) used Buddhaghosa's (1991; see also Ortner, Kilner, \& Zelazo, 2007)

124 definition of equanimity, which refers to "a balance of arousal without hyperexcitability or

125 fatigue" (p. 2). According to this definition, equanimity involves lower emotional interference

126 (Ortner et al., 2007), greater emotional stability (Taylor et al., 2011), greater inner peace

127 (Dambrun et al., 2012), and reduced general stress (Grossman et al., 2004). When adopted in

128 stressful situations, equanimity makes it possible for a person to remain calm and to make

129 decisions and follow behaviors that are the least contaminated by stress and arousal as possible.

130 Equanimity can also be considered in terms of a motivational approach (Hadash et al.,

131 2016). Hadash and colleagues used Olendzki's (2006) definition of equanimity: "an intentional

132 stance to neither hold on to pleasant experience nor push away unpleasant experience" (Hadash

133 et al., 2016, p. 3). They proposed the Decoupling Model of Equanimity, which conceptually

134 defines equanimity as the decoupling of desire (i.e., wanting or not wanting) from the hedonic

135 tone of experience. Here, the hedonic tone refers to the evaluation of the pleasantness of an 
136 object or situation, and can be understood as the valence of stimuli. Similarly, Vago and

137 Silbersweig (2012) described equanimity as "impartiality without bias or discrimination arising

138 from a sense of detachment from the attraction or aversion to ongoing experience” (p. 2).

139 Mindfulness has been found to decouple initial automatic approach/avoidance craving reactions

140 from their hedonic tone (e.g., alcohol; see Ostafin, Bauer, \& Myxter, 2012), because according to

141 this definition of equanimity, the approach/avoidance reaction is decreased (Papies et al., 2012).

142 As we have focused on equanimity as a quality of a balanced mind, the description of

143 equanimity as an even-minded state of mind and as the decoupling of desire from hedonic tone

144 also seems to encompass other definitions of equanimity. As was suggested above, equanimity

145 and mindfulness appear to be positively and significantly related to each other, without being

146 synonymous (Desbordes et al., 2015). Mindfulness has been described as the process or ability

147 of, paying attention to moment-by-moment experience (Kabat-Zinn, 1990), but its definition,

148 mechanisms, and components are much broader, leading to a wide range of operationalization

149 (e.g., Chiesa, 2013; Mikulas, 2011). Equanimity is a quality that may be developed through

150 mindful attention, but to date, studies have been more interested in showing the different

151 consequences of mindfulness on emotion regulation in general. Indeed, mindfulness-based

152 meditation has been linked to better emotional regulation (Kumar et al., 2008; Robins et al.,

153 2012), lower emotional reactivity (Farb et al., 2010), higher positive states and lower negative

154 states in response to stimuli (e.g., Erisman \& Roemer, 2010), improved emotional stability (Lee

155 et al., 2014; Taylor et al., 2011), and a decrease in individuals' subjective ratings of their

156 emotional reactions towards positive and negative stimuli (Taylor et al., 2011).

157 Noting the wide variety of outcomes and processes which have been measured so far, we

158 propose to specifically identify equanimity as a distinct emotion regulation pattern. The 
159 identification of equanimity would allow several things. First, equanimity could help to

160 understand observed patterns of emotion regulation that were not previously fully understood by

161 competing models, and thus to explain several results of prior mindfulness studies (see Juneau et

162 al., in press for a more thorough discussion of this issue). Second, the quality of equanimity

163 could be distinguished from the mechanisms involved in the practice of mindfulness, such as

164 decentering, non-judgment, or non-reactivity, thus enhancing the knowledge of how a state of

165 mindfulness develops. Finally, the study of equanimity could also help to identify the benefits of

166 sustainable happiness (Dambrun et al., 2012) as opposed to a fluctuating happiness based on the

167 pursuit of pleasure which also has adverse effects on the individual (e.g., Ryan \& Deci, 2001).

168 However, the literature has rarely made connections between the relevant outcomes of the

169 mindful practice of equanimity. In order to deepen and expand the study of equanimity, it is

170 necessary to be able to measure it. The few existing equanimity scales are based on definitions of

171 equanimity that share some similarities, but which also contain some differences. The first of

172 these, the Self-Other Four Immeasurables (SOFI; Kraus \& Sears, 2008), seeks to capture

173 participants' scores for each of the Four Immeasurables. For the equanimity subscale,

174 participants have to rate if they thought, felt, or acted with acceptance or its opposites (i.e.,

175 indifference or apathy). Equanimity is suggested as synonymous with an acceptance of the self

176 and of others. Moreover, the results and conclusion of the study placed greater emphasis on the

177 distinction between positive and negative qualities related to oneself and others (see Kraus \&

178 Sears, 2008). Considering more recent studies (Desbordes et al., 2015; Hadash et al., 2017;

179 Weber \& Lowe, 2018), it does not seem possible to propose equanimity as only representing a

180 synonymous of acceptance. Indeed, acceptance is defined as "experiencing events fully and 
181 without defense, as they are" (Hayes, 1994, p. 30) and it seems to be an important prerequisite

182 for equanimity, allowing a person to perceive all stimuli more evenly.

183 In other words, acceptance is a quality of living the experience, while equanimity is a form

184 of reactivity, with physiological (i.e., a stable and calm state of mind), emotional, and motivation

185 components. The acceptance of thoughts and emotions does not necessarily imply less intense

186 reactions. Considering this, Hadash and colleagues (2016) suggested the use of two existing

187 scales (i.e., anxiety sensitivity and cognitive reactivity to sadness) to assess reactivity in

188 equanimity, and added acceptance scales to build a complete equanimity assessment. This

189 proposal measures equanimity towards an unpleasant hedonic tone, as these authors explained.

190 Thus, it is necessary to create a scale that also considers the responsiveness to pleasant hedonic

191 tones.

Third, the Holistic Well Being Scale (Chan et al., 2014) aims to measure affliction and equanimity in a eudemonic view of well-being. It is theoretically based on spiritual care and vitality and, to our knowledge, has only been tried and validated among the Chinese population. The authors used a more global definition, of equanimity as "happiness despite an absence of pleasure" and "a state where a person abolishes his or her own sense of self" (p. 292). in life as they come"), mindful awareness (e.g., "I am able to notice changes in my mood"), general vitality (e.g., "I am full of energy"), and spiritual self-care (e.g., "I have a rich religious/spiritual life"). Considering the slight differences in definitions of equanimity, only the non-attachment questions seem to be in line with our equanimity approach. 
204 scale focuses on the barriers that prevent an individual from achieving equanimity by assessing 205 their beliefs and patterns of thoughts about how judgments arise (e.g., "If my feelings change 206 then I will change"; "I feel like the media influences the way I feel about others"). Since Weber 207 and Lower's paper was yet to be published when we began our research, we were unable to base 208 our work on their scale, so we independently developed the EQUA-S. Finally, the Spanish 209 subscale of Ecuanimidad (Moscoso \& Merino Soto, 2017), which consists of 6 items (e.g., "I feel 210 that I am a calm person, even in moments of stress and tension"; "Stress situations emotionally 211 disturb me" etc.), is based on the definition proposed by Desbordes et al. (2015).

212 Considering the existing work on equanimity, our scale aimed to measure equanimity 213 based on existing definitions and models, and specifically as a quality of response to emotional 214 stimuli with participants without meditation experience. We chose to focus on equanimity (a) as 215 the quality of being emotionally calm and balanced, regardless of pleasant or unpleasant 216 emotions, or in other words, as an even-minded state of mind (Desbordes et al., 2015), and (b) as 217 a decrease in emotional and motivational reactions towards pleasant stimuli, due to a decoupling 218 of desire and hedonic tone (Hadash et al., 2016).

219 We also hypothesized that equanimity can be related to fewer difficulties with emotional 220 regulation, and that it may explain the positive effect of mindfulness-based meditation on the 221 emotional regulatory effect of mindfulness, as well as on neuroticism, and alexithymia (Baer, 222 Smith, \& Allen, 2004 ; Ostafin et al., 2015; Siegling \& Petrides, 2014). Thus, equanimity - as a 223 more balanced emotional reaction toward stimuli - is theorized to be negatively related to 224 emotional negativity. Moreover, a high degree of fusion with someone's emotional state prevents 225 flexibility and detachment with regard to such stimuli (Corman et al., 2018), both of which are 226 prerequisites for equanimity. An individual's detachment from their emotional state would also 
227 reduce the frequency of impulse reactions, thus corresponding to the hedonic independence 228 component of equanimity.

229 The main aim of the present study was to develop and validate a self-reported equanimity 230 scale. We thus hypothesized the existence of two factors (even-minded state of mind and hedonic 231 independence components), which are related to distinct psychological constructs. This study 232 also aimed to investigate the possible relationships between equanimity and mental health. By 233 reducing craving and increasing emotional regulation, equanimity, as a state of hedonic 234 independence, can be a valuable mechanism in addressing addictive behaviors (Berridge \& 235 Kringelbach, 2008; Robinson \& Berridge, 2000). We predicted that hedonic independence, 236 which is closely related to a decrease in the approach reaction to pleasant experiences, would be 237 negatively and significantly related to addictive behaviors. Finally, according to Desbordes et al. 238 (2015), equanimity implies non-judgment, non-reactivity, and less automatic behavior in general. 239 Thus, we predicted that equanimity as an even-minded state would be positively associated with 240 the non-reactive and non-judging component of mindfulness, and with efficient coping strategies 241 (e.g., positive refocusing; see also Jermann, Van der Linden, d'Acremont, \& Zermatten, 2006).

\section{Materials \& Methods}

243 Participants

244 We recruited 265 adults in France $\left(N_{\text {women }}=175\right)$, with ages ranging from 18 to 73 years $245(M=34.81, S D=15.17)$. Using GPower (version 3.0.10), we estimated the required sample size 246 for sufficient correlations power (90\%). On the basis of the correlation between the FFMQ and 247 neuroticism reported by Siegling and Petrides; $r=.47$ (Siegling \& Petrides, 2014), the minimum 248 required sample size was calculated at 30 . The participants were recruited by 150 students from 249 the University of Clermont Auvergne. The students were asked to leave the questionnaire and 250 consent form for 24 hours in the participants' homes so that the participants could complete them 
251 while alone and undisturbed. To ensure that the questionnaire would not take too long to 252 complete, we decided to split the participants into two samples. Both samples answered the 253 equanimity scale, the FFMQ, and demographic questions. The participants in sample A answered 254 the psychological constructs questionnaire, while the participants in sample B answered 255 questions about addictive behaviors (see Table 1 for descriptions of each sample). Ethical 256 approval for the study was granted by the Clermont Auvergne University Ethical and Research 257 Committee (ref IRB00011450-2018621), and all procedures performed were in accordance with 258 the 1964 Helsinki declaration. All participants provided written informed consent prior to 259 participating in the study.

260

261

[Insert Table 1 here]

262

263 Scale Development

264 Based on the literature review, 42 candidate items were created to correspond to existing 265 definitions. Some of these items were inspired by the "Ecuanimidad" subscale (Moscoso \& 266 Merino Soto, 2017). Three judges who were familiar with the concept of equanimity individually 267 evaluated all these items before discussing their choices together. In the end, 25 were deemed to 268 be sufficiently relevant to be included. Of the 25 items, 12 were designed to assess the approach 269 to equanimity proposed by Desbordes et al. (2015), which we labeled "even-minded state of 270 mind". The remaining 13 items were inspired by the conceptualization of equanimity developed 271 by Hadash et al. (2016), which we termed "hedonic independence". The participants answered 272 using a 5 -point Likert scale $(1=$ never or very rarely to $5=$ very often or always $)$.

\section{Measures}


Several constructs were measured in order to ensure the convergent validity of the

275 equanimity scale (see Table 2). We used the available French version for each scale. We

276 assessed mindfulness (Five Facets Mindfulness Questionnaire, FFMQ; Heeren, Douilliez,

277 Peschard, Debrauwere, \& Philippot, 2011), hyper-sensitivity (Highly Sensitive Child Scale,

278 HSC; Pluess et al., 2018), the avoidance and fusion of internal events (Avoidance and Fusion

279 Questionnaire, AFQ; Corman et al., 2018), impulsivity (Barratt Impulsivity Scale, BIS-10; Baylé

280 et al., 2000), personality (Big Five Inventory, BFI; Plaisant, Courtois, Réveillère, Mendelsohn,

281 \& John, 2010), alexithymia (Toronto Alexithymia Scale, TAS-20; Loas, Otmani, Verrier,

282 Fremaux, \& Marchand, 1996), and sensitivity to punishment and reward (Sensitivity to

283 Punishment and Sensitivity to Reward Questionnaire, SPSRQ; Lardi, Billieux, d'Acremont, \&

284 Linden, 2008). Finally, we measured the relationships between equanimity and various health

285 outcomes via three scales: (1) the frequency of behaviors based on a list of 16 potential addictive

286 or problematic behaviors (e.g., video games, tobacco, etc.); (2) the frequency of eating addictions

287 (Addictive Intensity Evaluation Questionnaire, AIEQ; Décamps, Battaglia, \& Idier, 2010), and

288 (3) emotional regulation strategies (Cognitive Emotion Regulation Questionnaire, CERQ;

289 Jermann et al., 2006 and the suppression subscale of the Emotion Regulation Questionnaire

290 ERQ; Christophe et al., 2009).

\section{Results}

292

293 Exploratory Factor Analysis and Item Selection

Using SPSS Statistic 24, factor analysis with oblimin rotation of the 12 items selected to assess the even-minded state revealed a two-factor solution. The Kaiser measure of sampling adequacy (KMO) was .84. Based on the Eigenvalue and the Screen plot, a one-factor model

297 appeared to provide the best fit for the data $(E V=4.28$ for the first factor, and 1.42 for the 
298 second). We ran another analysis by forcing a one-factor extraction. Three items failed to load 299 sufficiently on the first factor (i.e., a factor loading of less than .50). A second analysis was 300 therefore computed with the remaining nine items. This analysis revealed a first factor solution 301 with one item loading less than .50. Once this item had been withdrawn, a final analysis revealed 302 a clear one-factor solution of eight items with a Kaiser measure of sampling adequacy of .85. All 303 the items loaded appropriately on the single factor (factor loadings ranged from .55 to .72 , see 304 Table 3).

305 The 13 items selected to assess hedonic independence were entered into a factor analysis 306 with oblimin rotation. The KMO was .77, with an Eigenvalue of 3.6 for the first factor, and 1.3

307 for the second. Based on the Eigenvalue and the Screen plot, a one-factor model appeared to 308 provide the best fit for the data. Seven items failed to load sufficiently on this factor (i.e., a factor 309 loading of less than .50). A second analysis was computed with the remaining seven items which 310 revealed a clear one-factor solution, with all the items loading appropriately on a single factor 311 (factor loading ranged from .54 to .71, see Table 3), and a Kaiser measure of sampling adequacy 312 of .80 .

\section{Are Even-Minded State of Mind and Hedonic Independence Distinct Constructs?}

To answer this question, we performed a new factor analysis using all the items from the two scales. Kaiser's measure of sampling adequacy was .80. Based on the Eigenvalues and an examination of the screen plot, this analysis revealed two factors, with the first factor accounting for $26.2 \%$ of the explained variance, and comprising all the items that assess even-minded state 
321 of mind. The second factor accounted for $17.5 \%$ of the explained variance and comprising items

322 that assess hedonic independence. Consequently, even-minded state of mind and hedonic

323 independence were shown to be two distinct constructs. Although the two scales correlated

324 significantly $(r=.174, p=.004)$, the size of the correlation was small $(d=.35)$.

325 The internal consistency of the two subscales was examined using Cronbach's alpha. For

326 the even-minded state of mind, Cronbach's alpha was equal to 0.81 , while for hedonic

327 independence, it was 0.74 . Thus, the two subscales of the EQUA-S had satisfactory internal

328 consistency (see Table 2).

329 Convergent validity with relevant psychological constructs

330 In order to assess convergent validity while controlling for each subscale of equanimity

331 (e.g., even-minded state while controlling for hedonic independence, and vice versa), we

332 calculated the partial correlation between the two subscales of equanimity and the relevant

333 psychological constructs (see Table 4). In the case of the FFMQ, the even-minded state was

334 related to nonreacting, to nonjudging, and to acting with awareness. We also found partial

335 negative correlations between the even-minded state of mind and the hyper-sensitivity score, one

336 subscale of alexithymia (i.e., identifying emotions), and the avoidance and fusion scale. Finally,

337 we identified a very strong negative correlation between the even-minded state of mind

338 component and neuroticism $(\beta=-.74, p=.000)$. In order to test the robustness of the above

339 findings, we replicated our analyses controlling for neuroticism, age, and sex. The correlation

340 between the even-minded state of mind and nonreacting remained significant $(\beta=.38, p=.000)$,

341 and the correlation was still marginally significant in relation to the avoidance and fusion

342 questionnaire $(\beta=-.23, p=.054)$. However, the correlations between the even-minded state of

343 mind and the other components of the FFMQ (i.e., nonjudging, acting with awareness) as well as 
344 the alexithymia identifying emotions subscale and hyper-sensitivity failed to reach significance.

345 Thus, our even-minded state subscale was found to be most closely related to nonreacting.

346 When the even-minded state of mind was controlled for, hedonic independence was

347 robustly and positively related to the acting with awareness component of the FFMQ. Hedonic

348 independence was also significantly and negatively related to hyper-sensitivity, to the avoidance

349 and fusion scale, to motor impulsivity, and to sensitivity to reward and punishment. In addition,

350 hedonic independence was positively and significantly related to conscientiousness. When age

351 and sex were controlled for, similar results were reached, except in the cases of the sensitivity to

352 punishment and the conscientiousness subscale, which failed to reach significance. Analyses

353 with cognitive and non-planned impulsivity were not interpreted due to their low internal

354 reliability (see Table 2).

355

356

[Insert Table 4 here]

357

358

Relations with health outcomes

359

Partial correlations (see Table 4) reveal that among the emotional regulation strategies

360

assessed by the CERQ and the ERQ, even-minded state of mind was positively and significantly

361

correlated with adaptive regulation strategies (i.e., positive reappraisal, refocus on planning,

362

putting into perspective, and acceptance), and negatively related to inadequate strategies (i.e.,

363

rumination, catastrophizing). When we controlled for age, sex and neuroticism, the same results

364

were found, except in the case of refocus on planning and rumination.

365

Hedonic independence was significantly correlated with positive refocusing, refocus on

planning, and rumination. When age and sex were controlled for, similar results emerged, except 
367 in the case of rumination. Finally, hedonic independence was significantly and negatively related

368 to addictive behaviors and to problematic eating behaviors (i.e., AIEQ). We found similar results

369 when we controlled for age and sex.

\section{Correlation with socio-demographic variables}

371 We combined the two samples (A and B) into a single data set in order to measure

372 correlations with the demographic variables. The results of a t-test showed a significant

373 difference between men and women in relation to the even-minded state of mind. Women had a

374 slightly lower score $(M=2.81, S D=.75)$ than men $(M=3.28, S D=.68), t(262)=-4.93, p=$

$375.001, d=.63$. We found no significant difference on the hedonic independence subscale.

376 A correlation analysis revealed a significant relation between the hedonic independence subscale

377 and age $(r=.29, p=.001)$, but no relation with age and even-minded state of mind. A t-test

378 showed a significant difference, at the level of hedonic independence, between participants

379 indicating that they had a religion $(M=3.98, S D=.55)$, and participants indicating that they did

$380 \operatorname{not}(M=3.82, S D=.64), t(262)=2.05, p=.042, d=-.27$. We found no correlation between

381 profession and language, either with mindfulness frequency, even-minded state of mind, or the

382 hedonic independence state.

383 Discussion

In this study, we aimed to validate a scale measuring equanimity in a population of nonmeditators. Based on existing theories, we proposed two related but distinct components of equanimity: (1) even-minded state of mind, and (2) hedonic independence. As was predicted, a

387 two-factor model fitted well with the data. These two factors were positively correlated with 
389 distinct correlations with other measures as well as through a factor analysis. In addition, these

390 two components of equanimity displayed adequate internal consistency.

391 The first component refers to equanimity as an even-minded state of mind, which means an

392 individual staying calm and feeling low stress, irrespective of the emotional evaluation of the

393 situation or the stimuli. However, we found, first, that the even-minded state of mind shared a

394 large amount of variance with neuroticism, which has been described as the opposite of

395 emotional stability (e.g., Gosling, Rentfrow \& Swann, 2003). Second, we identified a robust

396 relationship between this component of equanimity and adaptive emotional regulation strategies,

397 thus confirming that equanimity is a quality involved in emotional regulation. Third, we also

398 found a robust relationship with nonreacting, which is a central component of mindfulness

399 defined as letting thoughts and feelings pass without getting caught up in them (Baer et al.,

400 2008). Equanimity - as an observation of someone's responses to emotional stimuli - will

401 prevent useless and unhelpful reactions. Fourth, as expected, we also found a negative significant

402 relationship between the even-minded state of mind and the avoidance and fusion questionnaire.

403 Indeed, a weaker fusion with one's thoughts and feelings has been found to be related to both

404 greater mindfulness (Corman et al., 2018), and greater psychological flexibility (Hayes et al.,

405 2006), thus suggesting that an even-minded state of mind could be a protective health factor.

406 We termed the second component "hedonic independence" because it refers to the absence

407 of actions or reactions oriented by the hedonic valence of stimuli or situations. This component

408 was also found to correlate significantly and negatively with the avoidance and fusion

409 questionnaire. Thus, decentering appears to be a meaningful component in developing

410 equanimity (Desbordes et al., 2015). The hedonic independence component was more

411 significantly related to addictive measures than the even-minded state of mind had been. Hedonic 
412 independence was also associated with a lower sensitivity to reward, which is a risk factor for 413 addictions (Dissabandara et al., 2014; Eichen et al., 2016). Indeed, “approaching” or "wanting”

414 reactions to rewarding stimuli, as in the hedonic principle, could be adaptive (Berridge, \&

415 Kringelbach, 2008), or maladaptive by overriding the reflective system that controls a person's

416 long-term goals (Bechara, 2005). These results highlight the possible absence or decrease in

417 behavioral approach reactions to the hedonic tone of addictive stimuli. As Buddhist theories have 418 proposed, developing equanimity can be an efficient way of reducing general craving by 419 dampening the response to its hedonic tone.

420 Finally, the low correlation between the two subscales requires further investigation. This 421 correlation could be higher on meditators because the specific practice of mindfulness increases 422 both aspects of equanimity. In our study, the mean score was slightly higher for the HI subscale 423 in the general population tested. It is possible that in the general population, one of the two 424 components is more prevalent. However, additional studies are needed to understand how these 425 two components develop over time.

426 Moreover, Weber (2019) recently described equanimity as a way to react to our inner 427 judgements which can also extend outwards towards acceptance of the judgements of others.

428 Inner equanimity has been defined as "open acceptance or non-reactivity towards our 429 discrimination faculties" (ibid., p.5), while external equanimity is the acceptance of other 430 peoples' discriminatory faculties (Weber, 2019; Weber \& Lowe, 2018). In this theoretical 431 context, the EQUA-S seems to be more oriented towards inner equanimity, and could 432 subsequently be expanded to others as suggested by Weber (2019). 
Overall, the EQUA-S represents a useful tool for researchers who wish to study

434 435 area.

\section{Limitations and future directions \\ Limitations and future directions}

437

440 441

442

443

444

445 446

447 448

449

450

451

452

453

454

455 hypothesis in future research.

equanimity. We hope that this new instrument will help to stimulate research in this promising

Some limitations of this study must be acknowledged. First, our sample only concerned the general population, and we did not control for meditation experience. Nevertheless, this also highlights the relevance of the concept of equanimity and the validity of such a scale in evaluating the impact of individual differences in equanimity on health outcomes in a nonmeditator population. Another recent study has examined the relation between experience in mindfulness and equanimity (Juneau et al., in press).

Moreover, the strong link between the even-minded state of mind subscale and neuroticism requires further exploration and explanation. It is possible that this relationship is connected to the dimension of emotional stability that is assessed by both the even-minded state of mind and neuroticism. If this is the case, then this relationship should disappear when a scale that more directly measures emotional stability is statistically controlled. We will explore this

Further, this questionnaire was based on western definitions of equanimity and the authors do not claim that it measures the entire concept of equanimity. It will be useful to combine the existing scales in future, in order to explore their relationships and to improve understanding of this psychological construct. It would be interesting to examine the relations between components of the Equanimity Barriers Scale (EBS; Weber \& Lowe, 2018) and those of the EQUA-S in a future study. The relationship between cognitive measures of emotional responses and equanimity also need further research attention. Indeed, as Buddhist theories have 
456 implied, equanimity could moderate the cognitive evaluation of emotional stimuli by promoting

457 a more neutral evaluation. It is also possible that it leads to a decoupling of the evaluation of, and

458 the reaction to, a stimulus. Equanimity is an important component of the mindfulness state and

459 trait, but also of the regulation of emotion in general. This study did not address the impact of

460 equanimity on health as a distinct process of emotional regulation, nor the development of

461 equanimity, the barriers that inhibit it, or its relationship with mindfulness-based practice.

462

463

464 Conclusions

465 The objective of this study was to develop a scale to specifically measure the quality of

466 equanimity. Testing on the general population and exploratory factor analyses suggested two

467 dimensions: an even-minded state of mind (E-MSM) dimension, and a hedonic independence

468 (HI) dimension. The scale has good convergent validity, and its components are related to health

469 outcomes. We therefore hope that the scale will be used in further validation studies, and that it

470 will allow the initiation of new studies on equanimity, a promising quality that can be developed

471 through mindfulness-based meditation.

472

473

474

475

476

477

478

479

480

Peer) reviewing PDF | (2020:03:46519:1:0:NEW 9 May 2020) 
481

\section{References}

483

484

485

486

487

488

489

490

491

492

493

494

495

496

497

498

499

500

501

502

503

504

505

506

507

508

Baer, R. A., Smith, G. T., \& Allen, K. B. (2004). Assessment of mindfulness by self-Report : The Kentucky inventory of mindfulness skills. Assessment, 11(3), 191-206. https://doi.org/10.1177/1073191104268029

Baer, R. A., Smith, G. T., Lykins, E., Button, D., Krietemeyer, J., Sauer, S., Walsh, E., Duggan, D., \& Williams, J. M. G. (2008). Construct validity of the five facet mindfulness questionnaire in meditating and nonmeditating samples. Assessment, 15(3), 329-342. https://doi.org/10.1177/1073191107313003

Baylé, F. J., Bourdel, M. C., Caci, H., Gorwood, P., Chignon, J. M., Adés, J., \& Lôo, H. (2000). [Factor analysis of french translation of the Barratt impulsivity scale (BIS-10)]. Canadian journal of psychiatry. Revue canadienne de psychiatrie, 45(2), 156-165. https://doi.org/10.1177/070674370004500206

Bechara, A. (2005). Decision making, impulse control and loss of willpower to resist drugs: A neurocognitive perspective. Nature Neuroscience, 8(11), 1458-1463. https://doi.org/10.1038/nn1584

Berridge, K. C., \& Kringelbach, M. L. (2008). Affective neuroscience of pleasure: Reward in humans and animals. Psychopharmacology, 199(3), 457-480. https://doi.org/10.1007/s00213-008-1099-6

Bodhi, B. (2012). Comprehensive manual of Abhidhamma: The Abhidhammattha Sangaha. Pariyatti Publishing. Onalaska, WA

Chan, C. H. Y., Chan, T. H. Y., Leung, P. P. Y., Brenner, M. J., Wong, V. P. Y., Leung, E. K. T., Wang, X., Lee, M. Y., Chan, J. S. M., \& Chan, C. L. W. (2014). Rethinking well-being in terms of affliction and equanimity: Development of a holistic well-being scale. Journal of Ethnic \& Cultural Diversity in Social Work, 23(3-4), 289-308. https://doi.org/10.1080/15313204.2014.932550

Chiesa, A. (2013). The difficulty of defining mindfulness : Current thought and critical issues. Mindfulness, 4(3), 255-268. https://doi.org/10.1007/s12671-012-0123-4

Christophe, V., Antoine, P., Leroy, T., \& Delelis, G. (2009). Évaluation de deux stratégies de régulation émotionnelle : La suppression expressive et la révaluation cognitive. Revue Européenne de Psychologie Appliquée/European Review of Applied Psychology, 59(1), 59-67.

https://doi.org/10.1016/j.erap.2008.07.001

Peer] reviewing PDF | (2020:03:46519:1:0:NEW 9 May 2020) 
509 Corman, M., Dambrun, M., Bay, J.-O., \& Peffault de La Tour, R. (2018). Adaptation française et analyse des

510

511

512

513

514

515

516

517

518

519

520

521

522

523

524

525

526

527

528

529

530

531

532

533

534

535

536 qualités psychométriques du questionnaire d'évitement et de fusion (AFQ) dans une population adulte. Annales Médico-psychologiques, revue psychiatrique, 177(4), 358-363. https://doi.org/10.1016/j.amp.2018.01.012

Dambrun, M., \& Ricard, M. (2011). Self-centeredness and selflessness : A theory of self-based psychological functioning and its consequences for happiness. Review of General Psychology, 15(2), 138-157. https://doi.org/10.1037/a0023059

Dambrun, M., Ricard, M., Després, G., Drelon, E., Gibelin, E., Gibelin, M., Loubeyre, M., Py, D., Delpy, A., Garibbo, C., Bray, E., Lac, G., \& Michaux, O. (2012). Measuring happiness: From fluctuating happiness to authentic-durable happiness. Frontiers in Psychology, 3. https://doi.org/10.3389/fpsyg.2012.00016

Décamps, G., Battaglia, N., \& Idier, L. (2010). Élaboration du questionnaire de mesure de l'intensité des conduites addictives (QMICA): Évaluation des addictions et co-addictions avec et sans substances. Psychologie Française, 55(4), 279-294. https://doi.org/10.1016/j.psfr.2010.06.001

Desbordes, G., Gard, T., Hoge, E. A., Hölzel, B. K., Kerr, C., Lazar, S. W., Olendzki, A., \& Vago, D. R. (2015). Moving Beyond Mindfulness: Defining equanimity as an outcome measure in meditation and contemplative research. Mindfulness, 6(2), 356-372. https://doi.org/10.1007/s12671-013-0269-8

Dissabandara, L. O., Loxton, N. J., Dias, S. R., Dodd, P. R., Daglish, M., \& Stadlin, A. (2014). Dependent heroin use and associated risky behaviour: The role of rash impulsiveness and reward sensitivity. Addictive Behaviors, 39(1), 71-76. https://doi.org/10.1016/j.addbeh.2013.06.009

Eichen, D. M., Chen, E. Y., Schmitz, M. F., Arlt, J., \& McCloskey, M. S. (2016). Addiction vulnerability and binge eating in women: Exploring reward sensitivity, affect regulation, impulsivity \& weight/shape concerns. Personality and individual differences, 100, 16-22. https://doi.org/10.1016/j.paid.2016.03.084

Ekman, P., Davidson, R. J., Ricard, M., \& Wallace, B. A. (2005). Buddhist and psychological perspectives on emotions and well-being. Current Directions in Psychological Science, 14(2), 59-63.

Giluk, T. L. (2009). Mindfulness, Big Five personality, and affect: A meta-analysis. Personality and Individual Differences, 47(8), 805-811. https://doi.org/10.1016/j.paid.2009.06.026

Gosling, S. D., Rentfrow, P. J., \& Swann, W. B. (2003). A very brief measure of the Big-Five personality domains. Journal of Research in Personality, 37(6), 504-528. https://doi.org/10.1016/S0092-6566(03)00046-1

Peer) reviewing PDF | (2020:03:46519:1:0:NEW 9 May 2020) 
537 Grossman, P., Niemann, L., Schmidt, S., \& Walach, H. (2004). Mindfulness-based stress reduction and health

538

539

540

541

542

543

544

545

546

547

548

549

550

551

552

553

554

555

556

557

558

559

560

561

562

563 benefits: A meta-analysis. Journal of Psychosomatic Research, 57(1), 35-43.

https://doi.org/10.1016/S0022-3999(03)00573-7

Groves, P., \& Farmer, R. (1994). Buddhism and addictions. Addiction Research, 2(2), 183-194. https://doi.org/10.3109/16066359409109142

Gu, J., Strauss, C., Bond, R., \& Cavanagh, K. (2015). How do mindfulness-based cognitive therapy and mindfulness-based stress reduction improve mental health and wellbeing? A systematic review and metaanalysis of mediation studies. Clinical Psychology Review, 37, 1-12. https://doi.org/10.1016/j.cpr.2015.01.006

Gyatso, G. K. (2002). Understanding the mind: Lorig, an explanation of the nature and functions of the mind. Motilal Banarsidass Publications. New Delhi, India.

Hadash, Y., Segev, N., Tanay, G., Goldstein, P., \& Bernstein, A. (2016). The decoupling model of equanimity: Theory, measurement, and test in a mindfulness intervention. Mindfulness, 7(5), 1214-1226. https://doi.org/10.1007/s12671-016-0564-2

Hayes, S. C., Luoma, J. B., Bond, F. W., Masuda, A., \& Lillis, J. (2006). Acceptance and commitment therapy: Model, processes and outcomes. Behaviour Research and Therapy, 44(1), 1-25. https://doi.org/10.1016/j.brat.2005.06.006

Heeren, A., Douilliez, C., Peschard, V., Debrauwere, L., \& Philippot, P. (2011). Cross-cultural validity of the Five Facets Mindfulness Questionnaire: Adaptation and validation in a French-speaking sample. Revue Européenne de Psychologie Appliquée/European Review of Applied Psychology, 61(3), 147-151. https://doi.org/10.1016/j.erap.2011.02.001

Holzel, B. K., Lazar, S. W., Gard, T., Schuman-Olivier, Z., Vago, D. R., \& Ott, U. (2011). How does mindfulness meditation work? Proposing mechanisms of action from a conceptual and neural perspective. Perspectives on Psychological Science, 6(6), 537-559. https://doi.org/10.1177/1745691611419671

Jermann, F., Van der Linden, M., d'Acremont, M., \& Zermatten, A. (2006). Cognitive Emotion Regulation Questionnaire (CERQ). European Journal of Psychological Assessment, 22(2), 126-131. https://doi.org/10.1027/1015-5759.22.2.126

Peer) reviewing PDF | (2020:03:46519:1:0:NEW 9 May 2020) 
564 Juneau, C., Shankland, R. \& Dambrun, M. (in press). Trait and State Equanimity: The Effect of mindfulness-based 565 meditation practice. Mindfulness

566 Kraus, S., \& Sears, S. (2008). Measuring the Immeasurables: Development and initial validation of the Self-Other

567

568

569

570

571

572

573

574

575

576

577

578

579

580

581

582

583

584

585

586

587

588

589

590

591
Four Immeasurables (SOFI) scale based on Buddhist teachings on loving kindness, compassion, joy, and equanimity. Social Indicators Research, 92(1), 169. https://doi.org/10.1007/s11205-008-9300-1

Lacaille, J., Ly, J., Zacchia, N., Bourkas, S., Glaser, E., \& Knäuper, B. (2014). The effects of three mindfulness skills on chocolate cravings. Appetite, 76, 101-112. https://doi.org/10.1016/j.appet.2014.01.072

Lardi, C., Billieux, J., d'Acremont, M., \& van der Linden, M. (2008). A French adaptation of a short version of the Sensitivity to Punishment and Sensitivity to Reward Questionnaire (SPSRQ). Personality and Individual Differences, 45(8), 722-725. https://doi.org/10.1016/j.paid.2008.07.019

Loas, G., Otmani, O., Verrier, A., Fremaux, D., \& Marchand, M. P. (1996). Factor analysis of the French version of the 20-ltem Toronto Alexithymia Scale (TAS-20). Psychopathology, 29(2), 139-144. https://doi.org/10.1159/000284983

Mikulas, W. L. (2011). Mindfulness : Significant common confusions. Mindfulness, 2(1), 1-7. https://doi.org/10.1007/s12671-010-0036-z

Moscoso, M. S., \& Merino Soto, C. (2017). Construcción y validez de contenido del Inventario de Mindfulness y Ecuanimidad : Una perspectiva iberoamericana. Mindfulness \& Compassion, 2(1), 9-16. https://doi.org/10.1016/j.mincom.2017.01.001

Olendzki, A. (2006). The transformative impact of non-self. In D. K. Nauriyal, M. S. Drummond \& Y. B. Lal (Eds.), Buddhist thought and applied psychological research: Transcending the boundaries (pp. 250-261). New York, NY: Routledge.. https://doi.org/10.4324/9780203098899-25

Ortner, C. N. M., Kilner, S. J., \& Zelazo, P. D. (2007a). Mindfulness meditation and reduced emotional interference on a cognitive task. Motivation and Emotion, 31(4), 271-283. https://doi.org/10.1007/s11031-007-9076-7

Ortner, C. N. M., Kilner, S. J., \& Zelazo, P. D. (2007b). Mindfulness meditation and reduced emotional interference on a cognitive task. Motivation and Emotion, 31(4), 271-283. https://doi.org/10.1007/s11031-007-9076-7

Ostafin, B. D., Bauer, C., \& Myxter, P. (2012). Mindfulness decouples the relation between automatic alcohol motivation and heavy drinking. Journal of Social and Clinical Psychology, 31(7), 729-745. https://doi.org/10.1521/jscp.2012.31.7.729

Peer) reviewing PDF | (2020:03:46519:1:0:NEW 9 May 2020) 
592 Ostafin, B. D., Robinson, M. D., \& Meier, B. P. (2015). Handbook of mindfulness and self-regulation. Springer. $593 \quad$ New York, NY.

594 Pagis, M. (2015). Evoking equanimity: Silent interaction rituals in Vipassana meditation retreats. Qualitative 595 Sociology, 38(1), 39-56. https://doi.org/10.1007/s11133-014-9295-7

596

597

598

599

600

601

602

603

604

605

606

607

608

609

610

611

612

613

614

615

616

617

618

619 Psychological and Personality Science, 3(3), 291-299. https://doi.org/10.1177/1948550611419031

Plaisant, O., Courtois, R., Réveillère, C., Mendelsohn, G. A., \& John, O. P. (2010). Validation par analyse factorielle du Big Five Inventory français (BFI-Fr). Analyse convergente avec le NEO-PI-R. Annales Médico-psychologiques, revue psychiatrique, 168(2), 97-106. https://doi.org/10.1016/j.amp.2009.09.003

Pluess, M., Assary, E., Lionetti, F., Lester, K. J., Krapohl, E., Aron, E. N., \& Aron, A. (2018). Environmental sensitivity in children: Development of the Highly Sensitive Child Scale and identification of sensitivity groups. Developmental Psychology, 54(1), 51-70. https://doi.org/10.1037/dev0000406

Robinson, T. E., \& Berridge, K. C. (2000). The psychology and neurobiology of addiction : An incentivesensitization view. Addiction, 95(8s2), 91-117. https://doi.org/10.1046/j.1360-0443.95.8s2.19.x

Sedlmeier, P., Eberth, J., Schwarz, M., Zimmermann, D., Haarig, F., Jaeger, S., \& Kunze, S. (2012). The psychological effects of meditation: A meta-analysis. Psychological Bulletin, 138(6), 1139-1171. https://doi.org/10.1037/a0028168

Siegling, A. B., \& Petrides, K. V. (2014). Measures of trait mindfulness: Convergent validity, shared dimensionality, and linkages to the five-factor model. Frontiers in Psychology, 5. https://doi.org/10.3389/fpsyg.2014.01164

Skinner, M. D., \& Aubin, H.-J. (2010). Craving's place in addiction theory: Contributions of the major models. Neuroscience \& Biobehavioral Reviews, 34(4), 606-623. https://doi.org/10.1016/j.neubiorev.2009.11.024

Taylor, V. A., Grant, J., Daneault, V., Scavone, G., Breton, E., Roffe-Vidal, S., Courtemanche, J., Lavarenne, A. S., \& Beauregard, M. (2011). Impact of mindfulness on the neural responses to emotional pictures in experienced and beginner meditators. NeuroImage, 57(4), 1524-1533. https://doi.org/10.1016/j.neuroimage.2011.06.001

Vago, D. R., \& Silbersweig, D. A. (2012). Self-awareness, self-regulation, and self-transcendence (S-ART): A framework for understanding the neurobiological mechanisms of mindfulness. Frontiers in Human Neuroscience, 6, 296. https://doi.org/10.3389/fnhum.2012.00296 
620 Wallace, B. A. (2010). The Four Immeasurables: Practices to open the heart. Snow Lion Publications. Ithaca, NY.

621 Weber, J. (2017). Mindfulness is not enough: Why equanimity holds the key to compassion. Mindfulness \&

622 Compassion, 2(2), 149-158. https://doi.org/10.1016/j.mincom.2017.09.004

623 Weber, J., \& Lowe, M. (2018). Development and validation of the equanimity barriers scale [EBS]. Current

624 Psychology, 1-15 https://doi.org/10.1007/s12144-018-9969-5

625 Weber, J. (2019). Operationalising equanimity in clinical practice: A mindful approach, Clinical Psychology Forum, 626 322 , October.

627

628

629 
Table $\mathbf{1}$ (on next page)

Sample characteristics 
1 Table 1

2 Sample characteristics

\begin{tabular}{ccc} 
& \multicolumn{2}{c}{ Sample } \\
\cline { 2 - 3 } Characteristics & $\mathrm{A}$ & $\mathrm{B}$ \\
\hline $\mathrm{N}$ & 134 & 131 \\
\hline Age range (years) & $18-73$ & $18-70$ \\
\hline Age mean (years) & 35.1 & 34.5 \\
\hline Female (\%) & 60.4 & 72.3 \\
\hline Religious adherence (\%) & 45.6 & 45.5 \\
\hline Meditation practice (\%) & 17.9 & 10.8
\end{tabular}

3 
Table 2 (on next page)

List of scales and subscales from sample $A$ and $B$ 
1 Table 2

2 List of scales and subscales from samples $A$ and $B$

Scale

Subscale

Cronbach

Mean (SD)

Sample A

\begin{tabular}{|c|c|c|c|}
\hline EQUA-S & Even-minded state of mind & .85 & $3.10(.81)$ \\
\hline & Hedonic Independence & .75 & $3.87(.63)$ \\
\hline \multirow{5}{*}{ BFI } & Extraversion (E) & .82 & $3.15(.84)$ \\
\hline & Agreeableness (A) & .72 & $3.90(.57)$ \\
\hline & Concientiousness (C) & .78 & $3.59(.72)$ \\
\hline & Neuroticism $(\mathrm{N})$ & .84 & $3.00(.93)$ \\
\hline & Openness (O) & .73 & $3.53(.63)$ \\
\hline HSC & & .70 & $5.01(.82)$ \\
\hline \multirow{5}{*}{ FFMQ } & Observing & .80 & $3.26(.81)$ \\
\hline & Describing & .89 & $3.11(.90)$ \\
\hline & Nonreacting & .77 & $3.00(.72)$ \\
\hline & Acting with awareness & .86 & $3.35(.81)$ \\
\hline & Nonjudging & .84 & $3.17(.83)$ \\
\hline TAS & & .74 & $51.46(11.90)$ \\
\hline \multirow{10}{*}{ CERQ and ERQ } & Self-blame & .77 & $2.49(.89)$ \\
\hline & Acceptance & .66 & $3.46(.90)$ \\
\hline & Rumination & .71 & $2.99(.91)$ \\
\hline & Positive refocusing & .83 & $2.93(1.04)$ \\
\hline & Positive reappraisal & .79 & $3.63(.94)$ \\
\hline & Refocus on planning & .78 & $3.53(.89)$ \\
\hline & Putting into perspective & .78 & $3.70(.95)$ \\
\hline & Catastrophizing & .76 & $2.03(.96)$ \\
\hline & Blaming others & .77 & $1.95(.77)$ \\
\hline & Suppression & .82 & $2.68(.85)$ \\
\hline AFS & & .82 & $2.30(.50)$ \\
\hline \multirow[t]{2}{*}{ SPSRQ } & Punishment & .88 & $2.10(.58)$ \\
\hline & Reward & .83 & $2.16(.60)$ \\
\hline \multirow[t]{3}{*}{ BIS-10 } & Motor & .76 & $20.64(5.35)$ \\
\hline & Cognitive & .37 & $25.23(3.92)$ \\
\hline & Non planning & .52 & $25.44(4.48)$ \\
\hline
\end{tabular}

Sample B

\begin{tabular}{cccc}
\hline \multirow{2}{*}{ EQUA-S } & Even-minded state of mind & .73 & $2.85(.67)$ \\
\cline { 2 - 4 } & Hedonic Independence & .73 & $3.88(.62)$ \\
\hline HSC & & .67 & $5.13(.73)$ \\
\hline \multirow{2}{*}{ FFMQ } & Observing & .76 & $3.15(.78)$ \\
\cline { 2 - 4 } & Describing & .77 & $2.99(.68)$ \\
\cline { 2 - 4 } & Nonreacting & .63 & $2.66(.56)$ \\
\cline { 2 - 4 } & Acting with awareness & .86 & $3.33(.79)$ \\
\hline
\end{tabular}




\begin{tabular}{|c|c|c|}
\hline & Nonjudging & $3.01(.85)$ \\
\hline AIEQ & .90 & \\
\hline $\begin{array}{c}\text { Frequency of } \\
\text { addictive } \\
\text { behaviours }\end{array}$ & N.A & $50.38(8.25)$ \\
\hline
\end{tabular}

3 


\section{Table 3 (on next page)}

Factor loadings (F), means (M), standard deviation (SD), and item-total correlations (IT) for the 14-item 
1 Table 3

2 Factor loadings $(F)$, means $(M)$, standard deviation (SD), and item-total correlations (IT) for the 14-item

\begin{tabular}{|c|c|c|c|c|c|c|}
\hline Items & F1 & $\mathrm{F} 2$ & F3 & $\mathrm{M}$ & SD & IT \\
\hline \multicolumn{7}{|c|}{ Even-minded state of mind (E-MSM) } \\
\hline $\begin{array}{l}\text { 1. Whatever happens I remain serene } \\
\text { Quoi qu'il arrive, je reste serein }\end{array}$ & .72 & & & 2.90 & 1.08 & 0.17 \\
\hline $\begin{array}{l}\text { 2. I am not easily disturbed by something unexpected } \\
\text { Je ne suis pas facilement perturbé par un imprévu }\end{array}$ & .55 & & & 2.88 & 1.13 & 0.22 \\
\hline $\begin{array}{l}\text { 3. I can't hardly tolerate uncomfortable emotions } \\
\text { J'ai du mal à tolérer les émotions inconfortables (R) }\end{array}$ & -.56 & & .42 & 3.11 & 1.11 & 0.34 \\
\hline $\begin{array}{c}\text { 4. I can easily get carried away by an annoyance } \\
\text { Je peux facilement me laisser emporter par une } \\
\text { contrariété }(R)\end{array}$ & -.66 & & & 3.17 & 1.2 & 0.39 \\
\hline \multicolumn{7}{|l|}{$\begin{array}{c}\text { Je ressens que je suis une personne calme, même } \\
\text { dans des moments de stress et tension }\end{array}$} \\
\hline $\begin{array}{l}\text { 6. Stress situations emotionally disturb me } \\
\text { Les situations de stress me perturbent } \\
\text { émotionnellement }(R)\end{array}$ & -.65 & .37 & .34 & 3.35 & 1.18 & 0.36 \\
\hline \multicolumn{7}{|l|}{$\begin{array}{c}\text { Il est difficile pour moi d'être serein(e) pendant les } \\
\text { moments difficiles de la vie quotidienne }(R)\end{array}$} \\
\hline \multicolumn{7}{|l|}{$\begin{array}{c}\text { Je ressens que les problèmes dans ma vie sont } \\
\text { temporaires et qu'il existe des solutions }(R)\end{array}$} \\
\hline Full sub-scale & & & & 3.18 & 1.30 & \\
\hline \multicolumn{7}{|c|}{ Hedonic Independence (HI) } \\
\hline $\begin{array}{l}\text { 1. When I look forward to doing something pleasant, } \\
\text { I can only think about it } \\
\text { Lorsque j'anticipe de faire quelque chose de plaisant, } \\
\text { je ne pense qu'à ça (R) }\end{array}$ & .71 & & & 3.84 & .85 & .56 \\
\hline $\begin{array}{l}\text { 2. When I anticipate a situation or something that I } \\
\text { like, I get very excited } \\
\text { Lorsque j'anticipe quelque chose ou une situation } \\
\text { que j'aime, je suis très excité(e) (R) }\end{array}$ & .66 & & & 3.88 & .88 & .51 \\
\hline $\begin{array}{l}\text { 3. When I desire an object, I feel a strong attraction } \\
\text { to get it quickly } \\
\text { Lorsque je suis attiré par un objet qui me fait envie, } \\
\text { je ressens une forte attraction pour l'obtenir } \\
\text { rapidement }(R)\end{array}$ & .60 & & & 3.35 & 1.16 & .45 \\
\hline $\begin{array}{l}\text { 4. I am very excited when I am given something } \\
\text { pleasant (like a good surprise or a gift) or when } \\
\text { something pleasant happens to me. } \\
\text { Je suis très excité(e) lorsqu'il m'arrive ou que l'on } \\
\text { me donne quelque chose de plaisant (comme une } \\
\text { bonne surprise ou un cadeau) (R) }\end{array}$ & .54 & & -.52 & 3.94 & .90 & .37 \\
\hline $\begin{array}{l}\text { 5. I often wish to prolong the moments when I feel a } \\
\text { strong pleasure } \\
\text { Je souhaite souvent prolonger les moments où je }\end{array}$ & .60 & & & 4.32 & .86 & .47 \\
\hline
\end{tabular}


ressens un fort plaisir $(R)$

6. I can't stop doing something I like

.55

$.35 \quad 3.97$

.44

J'ai du mal à m'arrêter lorsque je fais quelque chose que j'aime $(R)$

Full sub-scale

$3.59 \quad 1.00$

4

$(R)=$ Reverse coded items 


\section{Table 4 (on next page)}

Correlations and partial correlations between Even-minded State of Mind (E-MSM), Hedonic Independence(HI), and various dependent variables 
$1 \quad$ Table 4

2 Correlations and partial correlations between Even-minded State of Mind (E-MSM), Hedonic

3 Independence(HI), and various dependent variables

4

\begin{tabular}{|c|c|c|c|c|c|}
\hline & \multirow[t]{2}{*}{ Sample } & \multicolumn{2}{|c|}{ E-MSM } & \multicolumn{2}{|c|}{$\mathrm{HI}$} \\
\hline & & $r$ & Partial $r$ & $r$ & Partial $r$ \\
\hline \multicolumn{6}{|l|}{$-F F M Q$} \\
\hline Observing & A \& B & .016 & .035 & -.103 & -.108 \\
\hline Describing & A \& B & .096 & .104 & -.035 & -.053 \\
\hline Acting with awareness & A \& B & $.223 * * *$ & $.193 *$ & $.210 * *$ & $.179 * *$ \\
\hline $\begin{array}{l}\text { Nonjudging of inner } \\
\text { experience }\end{array}$ & A \& B & $.296 * * *$ & $.279 * * *$ & $.136^{*}$ & .090 \\
\hline $\begin{array}{c}\text { Nonreacting to inner } \\
\text { experience }\end{array}$ & A \& B & $.540 * * *$ & $.526^{* * *}$ & $.164 * *$ & .084 \\
\hline$-H S C$ & A \& B & $-.416 * * *$ & $-.392 * * *$ & $-.23 * *$ & $-.180 * *$ \\
\hline$-T A S$ & $\mathrm{~A}$ & -.102 & -.085 & -.105 & -.088 \\
\hline Identifying emotions & A & $-.203 *$ & $-.181 *$ & -.150 & -.117 \\
\hline Describing emotions & A & -.028 & -.038 & .050 & .056 \\
\hline Externally oriented thinking & A & .026 & .050 & -.126 & -.133 \\
\hline$-A F S$ & $\mathrm{~A}$ & $-.435 * * *$ & $-.405 * * *$ & $-.314 * * *$ & $-.264 * *$ \\
\hline \multicolumn{6}{|l|}{ - SPSRQ } \\
\hline Sensitivity to punishment & A & $-.405 * * *$ & $-.375 * * *$ & $-.272 * *$ & $-.221 *$ \\
\hline Sensitivity to reward & A & -.013 & -.076 & $-.438 * * *$ & $-.443 * * *$ \\
\hline \multicolumn{6}{|l|}{$-C E R Q$} \\
\hline Self-blame & A & -.143 & -.124 & -.116 & -.092 \\
\hline Acceptance & A & $.327 * * *$ & $.317 * * *$ & .092 & .035 \\
\hline Rumination & A & $-.310 * * *$ & $-.277 * *$ & $-.254 * *$ & $-.211 *$ \\
\hline Positive refocusing & A & .151 & .187 & -.166 & $-.199 *$ \\
\hline Positive reappraisal & A & $.287 * *$ & $.313 * * *$ & -.107 & -.169 \\
\hline Refocus on planning & A & $.276^{* *}$ & $.330 * * *$ & $-.222 *$ & $-.288 * *$ \\
\hline Putting into perspective & A & $.339 * * *$ & $.351 * * *$ & -.034 & -.104 \\
\hline Catastrophizing & $\mathrm{A}$ & $-.365 * * *$ & $-.345 * * *$ & $-.171 *$ & -.114 \\
\hline Blaming others & A & -.136 & -.122 & -.095 & -.072 \\
\hline - ERQ Suppression & $\mathrm{A}$ & .052 & .065 & -.064 & -.075 \\
\hline \multicolumn{6}{|l|}{$-B F I$} \\
\hline E (Extraversion) & A & .016 & .040 & -.13 & -.136 \\
\hline A (Agreeableness) & A & .127 & .101 & .156 & .136 \\
\hline $\mathrm{C}$ (Concientiousness) & A & .117 & .079 & $.225 * *$ & $.208 *$ \\
\hline $\mathrm{N}$ (Neuroticism) & A & $-.739 * * *$ & $-.730 * * *$ & $-.181 *$ & -.070 \\
\hline O (Openness) & A & .061 & .070 & .044 & -.056 \\
\hline$-A I E Q$ & $\mathrm{~B}$ & -.118 & -.072 & $-.304 * * *$ & $-.299 * *$ \\
\hline $\begin{array}{c}\text { - Frequency of addictive } \\
\text { behaviors }\end{array}$ & $\mathrm{B}$ & -.125 & -.087 & $-.251 * *$ & $-.243 * *$ \\
\hline \multicolumn{6}{|l|}{$-B I S-10$} \\
\hline Motor & A & -.109 & -.051 & $-.339 * * *$ & $-.327 * * *$ \\
\hline Attentional & A & $-.185^{*}$ & -.142 & $-.279 * *$ & $-.254 * *$ \\
\hline Non-planning & A & $.267 * *$ & $.260 * *$ & .066 & .018 \\
\hline
\end{tabular}

6

Note: $* * * p<.001, * * p<.01 ; * p<.05$. Partial $r$ provides correlations, with the other factor of equanimity controlled for (i.e., E-MSM controlling for hedonic independence and HI controlling for E-MSM). 